\title{
O BRASIL DE BOLSONARO
}

\section{Bolsonaro's Brazil}

Fábio Luis Barbosa dos Santos Universidade Federal de São Paulo, Brasil

Informações do artigo

Recebido em 28/07/2020

Aceito em 25/10/2020

doi>: https://doi.org/10.25247/2447-861X.2020.n250.p448-470

Esta obra está licenciada com uma Licença Creative Commons Atribuição 4.0 Internacional.

\section{Como ser citado (modelo ABNT)}

SANTOS, F. L. B. O Brasil de Bolsonaro. Cadernos do CEAS: Revista Crítica de Humanidades.

Salvador/Recife, v. 45, n. 250, p. 448-470, maio/ago. 2020. DOI: https://doi.org/10.25247/2447-

861X.2020.n250.p448-470

\section{Resumo}

Este texto discute a conjuntura brasileira no início do segundo ano do governo Bolsonaro, quando eclodiu a pandemia do coronavírus. $O$ artigo se organiza em três seções. Na primeira parte, é analisada a natureza das gestões presidenciais petistas como premissa para interpretar a derrocada do partido, entre o impeachment de Rousseff em 2016 e a prisão de Lula dois anos depois. A segunda seção analisa o significado da eleição de Bolsonaro à luz das movimentações da classe dominante que estão em curso, bem como o projeto político do excapitão. A última seção examina os dilemas que a esquerda enfrenta na presente conjuntura. Entende-se que, para além dos personagens envolvidos, os acontecimentos recentes da política brasileira devem ser analisados à luz de uma inflexão das classes dominantes em uma direção que compromete a institucionalidade associada à Nova República. Discutem-se as causas desta inflexão, suas principais expressões políticas e os desafios que coloca para a esquerda.

Palavras-Chave: Brasil. Bolsonaro. Nova República. Partido dos Trabalhadores.

\section{Abstract}

Bolsonaro government, when the coronavirus pandemic broke out. The article is organized into three sections. In the first part, the nature of PT's presidential administrations is analyzed as a premise to interpret the collapse of the party, between the impeachment of Rousseff in 2016 and the arrest of Lula two years later. The second section analyzes the significance of Bolsonaro's election in light of the ongoing movements of the ruling class, as well as the former captain's political project. The last section examines the dilemmas that the left faces at the present juncture. It is understood that, in addition to the characters involved, recent events in Brazilian politics must be analyzed in the light of an inflection of the dominant classes in a direction that compromises the institutionality associated with the New Republic. The causes of this inflection, its main political expressions and the challenges it poses to the left are discussed.

Keywords: Brazil. Bolsonaro. New Republic. Worker's Party (PT) 


\section{Introdução}

Este texto discute a conjuntura brasileira no início do segundo ano do governo Bolsonaro, quando eclodiu a pandemia do coronavírus. O artigo se organiza em três seções. Na primeira parte, é analisada a natureza das gestões presidenciais petistas como premissa para interpretar a derrocada do partido, entre o impeachment de Rousseff em 2016 e a prisão de Lula dois anos depois. A segunda seção analisa o significado da eleição de Bolsonaro à luz das movimentações da classe dominante que estão em curso, bem como o projeto político do ex-capitão. A última seção examina os dilemas que a esquerda enfrenta na presente conjuntura. Entende-se que, para além dos personagens envolvidos, os acontecimentos recentes da política brasileira devem ser analisados à luz de uma inflexão das classes dominantes em uma direção que compromete a institucionalidade associada à Nova República. Discutem-se as causas desta inflexão, suas principais expressões políticas e os desafios que coloca para a esquerda.

\section{A natureza das gestões petistas}

Embora a chamada 'onda progressista' sul-americana fosse identificada corretamente em seu momento como uma reação ao neoliberalismo, é difícil sustentar que a prática petista dele se distanciou. No plano macroeconômico, o tripé meta inflacionária, superávit primário e câmbio flexível, estabelecido pelo plano de estabilização conhecido como 'Plano Real' em 1994, foi mantido. Esta arquitetura da austeridade foi complementada pela lei de responsabilidade fiscal: combatida pelo PT quando FHC a implementou em 2000, a lei permaneceu intocada e, em uma ironia da história, forneceu o pretexto para o processo de impeachment contra Rousseff em 2016.

Por outro lado, se compreendermos o neoliberalismo como uma tecnologia de governo das pessoas presidida pelo princípio da concorrência (DARDOT; LAVAL, 2010), a continuidade é igualmente evidente. As gestões petistas promoveram a inclusão pelo consumo como solução para problemas sociais - uma via individual, que mercantiliza direitos. Mesmo o Bolsa Família, principal programa social petista, apenas consolidou esquemas implementados sob FHC e expandiu sua cobertura. Como se sabe, o PRI mexicano foi pioneiro em implementar um programa desta natureza, depois da fraude eleitoral de 1988. Recentemente, diante da pandemia do coronavírus, o governo Bolsonaro se comprometeu a 
ampliar o programa. A financeirização de políticas públicas andou junto à expansão do crédito para as camadas populares. Entretanto, o acesso a bens de consumo não foi acompanhado do fortalecimento de bens e equipamentos públicos: nenhuma privatização foi revertida e formas de mercantilização de serviços públicos se aprofundaram na saúde (Ebserh), na educação (Prouni) e na previdência (reforma de 2003), para citar exemplos conhecidos. No conjunto, observou-se uma nova rodada de modernização dos padrões de consumo, cuja outra face é a perpetuação da concentração de renda e do mimetismo cultural, fenômeno antigo como o próprio subdesenvolvimento. Em 2018, o país tinha mais smartphones do que habitantes, o que foi explorado pela rede de fake news da campanha de Bolsonaro.

A particularidade das gestões petistas em relação às precedentes não foi a oposição ao neoliberalismo, mas suas estratégias de legitimação social e acumulação ampliada. 0 'modo lulista de regulação do conflito social' se articulou a um projeto 'neodesenvolvimentista', que teve como alicerce uma política de 'campeãs nacionais', visando fazer do Brasil um jogador global (global player). Estes aspectos diferenciam os governos PT em relação a seus precedentes tucanos, mas sobretudo, em relação aos seus sucessores.

O modo lulista de regulação do conflito social pode ser resumido como a combinação entre modestos ganhos para os extremos inferiores da pirâmide social brasileira (por meio de políticas de transferência de renda condicionada, de uma elevação do salário mínimo atrelada ao crescimento da economia e da expansão do crédito), com a reprodução ampliada do regime de acumulação financeira apoiado sobre bases extrativistas. A conjunção entre pequenos ganhos para os de baixo, com os lucros de sempre para os de cima, lastreou uma relativa pacificação social do país, que durou dez anos.

A hegemonia lulista apoiou-se sobre a articulação de duas formas distintas, porém complementares, de consentimento (BRAGA; SANTOS, 2019). Em primeiro lugar, o consentimento passivo das classes subalternas ao projeto de governo abraçado por uma burocracia sindical que, durante o período de crescimento econômico, soube garantir modestas, mas efetivas concessões aos trabalhadores. De maneira geral, o subproletariado semi-rural nos rincões do país foi beneficiado pelo Programa Bolsa Família, passando da extrema pobreza para a pobreza oficial. O precariado urbano beneficiou-se de aumentos do salário mínimo acima da inflação, e da criação de empregos formais. Por fim, no contexto de 
um mercado de trabalho aquecido, o proletariado sindicalmente organizado alcançou negociações coletivas vantajosas, tanto em termos salariais quanto em termos de benefícios trabalhistas. Em um país reputado por desigualdades abissais, estes discretos avanços foram suficientes para sedimentar o consentimento dos subalternos à regulação lulista. Ao mesmo tempo, o governo petista articulou concretamente os interesses da burocracia sindical, de lideranças dos movimentos sociais e de setores médios intelectualizados, criando as bases para um consentimento ativo ao lulismo, cujo lócus foi o aparelho de Estado (BRAGA, 2014). Além disso, por meio da ocupação de postos nos conselhos dos fundos de pensão e dos bancos públicos, a alta burocracia sindical 'financeirizou-se', isto é, fundiu seus interesses ao capital financeiro (OLIVEIRA, 2003).

Estas formas de legitimação do governo se costuraram a uma estratégia de acumulação autodescrita como 'neodesenvolvimentista', que teve como fulcro o apoio à internacionalização de grandes empresas de capital nacional ou sediadas no país, entendidas como vetores do desenvolvimento capitalista nacional: foi a política das 'campeãs nacionais'. Seus veículos principais foram a diplomacia empresarial praticada pelo Itamaraty, sobretudo na América do Sul, e a política de crédito do Banco Nacional de Desenvolvimento Econômico e Social (BNDES). Em seu auge, em 2010, os empréstimos do banco com esta finalidade superaram em duas vezes e meia a soma dos recursos movimentado pelo Banco Mundial e o Banco Interamericano de Desenvolvimento (BID) (LEOPOLDO, 2011). A ação do banco intensificou a concentração de capitais em setores da economia considerados internacionalmente competitivos, notavelmente no campo da exportação primária e da construção civil ${ }^{1}$. Este último setor também foi beneficiado pela Iniciativa de Integração Regional da Infraestrutura Sul-americana (IIRSA) no plano regional e pelo Programa de Aceleração do Crescimento (PAC) no plano doméstico, prevendo uma agenda de obras de infraestrutura. Por fim, o programa Minha Casa, Minha Vida, inspirado em um programa

\footnotetext{
${ }^{1}$ Para dar alguns exemplos: o banco proporcionou $\mathrm{R} \$ 6$ bilhões ao grupo JBS para aquisições no Brasil e no exterior, que o converteram no maior produtor de carne do mundo; $R \$ 2,4$ bilhões para a Votorantim Celulose adquirir a Aracruz Celulose, resultando também em uma das maiores produtoras de celulose, a Fibria; mais de $\mathrm{R} \$ 1,5$ bilhão para a fusão da Sadia com a Perdigão, tornando o grupo Brasil Foods o maior exportador mundial de frango (GARCIA, 2012). Entretanto, o protagonista da expansão mercantil brasileira foi a construção civil, setor que fez negócios em todos os países da América Latina, de Colômbia a Cuba, bem como em outras partes do mundo, com destaque para a África portuguesa.
} 
similar chileno, implementado sob Pinochet, estendeu o crédito habitacional a camadas populares.

Este movimento de internacionalização de corporações brasileiras, principalmente na América do Sul, correspondeu a um projeto político de liderança regional. A estratégia previa que a expansão dos negócios brasileiros serviria de alicerce à projeção política do país no cenário mundial (SANTOS, 2018). Deste ponto de vista, iniciativas venezuelanas como a ALBA, o Sucre, o Banco do Sul e a Telesur foram interpretadas como concorrentes e não complementares ao projeto brasileiro, que buscou construir consensos regionais em lugar de desafiar a hegemonia estadunidense. Sua proposta era a Unasul, não a Alba; equilibrar o FMI, não fazer o Banco do Sul; ser capa da 'The Economist', não construir a Telesur; ser um líder, não formar um time; entrar no G-8, não confrontá-lo. A mesma lógica presidiu sua atuação junto aos BRICS, como reconhecem seus quadros mais lúcidos (BATISTA JUNIOR, 2019).

É importante destacar que, a despeito da retórica neodesenvolvimentista, a matriz produtiva do país foi preservada, enquanto a dependência e a desindustrialização se acentuaram. O percentual das importações e exportações em relação ao PIB aumentou, assim como a mobilidade de capitais, o que denota maior abertura comercial e financeira, resultando em maior vulnerabilidade aos fluxos internacionais. Por outro lado, desde 1985, a participação industrial no PIB decresce no país, passando de $35,88 \%$ naquele ano para $13,13 \%$ em 2013. Naquele momento, o Brasil respondia por 2,8\% da produção industrial mundial, cifra que se reduziu a $1,7 \%$ nos anos 2000, estabilizando-se neste patamar até 2010 (UNITED NATIONS INDUSTRIAL DEVENLOPMENT ORGANIZATION, 2011). Naquele ano, relatório do Ministério da Fazenda classificava como commodities $64,6 \%$ das exportações brasileiras, cifra que em 1994 estava em torno de 50\% (ESPOSITO, 2017).

É possível dizer que, durante o ciclo de expansão econômica que se estendeu até o primeiro mandato de Rousseff, este "desenvolvimentismo neoliberal" (SAAD FILHO; MORAIS, 2018) avançou com relativo êxito. A expansão de negócios brasileiros correspondeu a um reconhecimento do protagonismo político do país, personificado na figura do presidente Lula, visto por Obama, em 2009, como o político mais popular do mundo (BRAZIL'S..., 2009). Entretanto, a conjunção entre desaceleração econômica e escândalos de corrupção, que escalou a partir de 2014, colocou este projeto na defensiva. Enquanto a economia brasileira entrava em recessão, numerosas denúncias explicitaram esquemas de corrupção envolvendo a Petrobras, empreiteiras, frigoríficos e outras 'campeãs nacionais', no 
país e no exterior. Estas revelações minaram a confiabilidade do governo e do partido que o comandava, mas também comprometeram os alicerces do projeto neodesenvolvimentista com que se identificavam². Precisamente, foram as 'campeãs nacionais' que protagonizaram escândalos de corrupção no Brasil e na região nos últimos anos: a operação Lava-Jato, manejada de modo acintosamente parcial contra o PT, revelou esquemas de propina envolvendo a Petrobras; Temer quase caiu em função do vazamento de conversas comprometedoras com o fundador do frigorífico JBS; a prisão de Lula teve como principal prova a espúria delação premiada do presidente da construtora OAS, cuja pena reduziu-se de 23 para 3 anos de cárcere ${ }^{3}$; enquanto no Peru, quatro ex-presidentes foram condenados à prisão em meio a denúncias envolvendo a Odebrecht, e um deles se matou.

As contradições econômicas, somadas à exposição das entranhas políticas, evidenciaram os limites do neodesenvolvimentismo. Em primeiro lugar, subestimou-se a dinâmica do capital no mundo contemporâneo, inclusive de setores nacionais, em sua maioria há muito tempo internacionalizados. Ao mesmo tempo, o governo calculava que a defesa dos interesses de uma 'burguesia interna' (BOITO JR.; BERRINGER, 2013) se traduziria em fidelidade política, reeditando, de certa maneira, a ilusão passada de uma burguesia nacional. Retrospectivamente, o caráter episódico e interessado deste apoio ficou claro, motivando uma das poucas autocríticas que Rousseff faz de seu primeiro governo, mais ousado do que Lula neste plano. Quando o esgotamento da conjuntura internacional favorável convergiu com a insatisfação doméstica, a articulação entre modos tradicionais de fazer negócios com formas conservadoras de fazer política, cobrou seu preço.

Porém, a defenestração do PT de Brasília não é compreensível sem integrar à análise um componente social: o esgotamento do modo lulista de regulação do conflito social, que

\footnotetext{
2 Por outro lado, diversos indícios questionavam a eficácia da estratégia das "campeãs nacionais". Em primeiro lugar, algumas empresas que receberam vultuosos aportes do BNDES passaram, pouco depois, para o controle internacional. Foi este o caso do conglomerado de bebidas Ambev, que se fundiu com uma corporação belga e teve sua sede transferida para este país; da EBX que se associou a empresas de capital chinês e coreano após aprovar grandes volumes de crédito público para seus projetos, entre outros casos (TAUTZ et al., 2010). Também houve situações como a operação da Odebrecht no Peru, que se autonomizaram: registrada legalmente como uma empresa local, já não tem projetos apoiados pelo BNDES, mas tampouco colabora para a exportação de serviços e produtos brasileiros. No conjunto, há escassa evidência de que o apoio prestado a estes negócios correspondeu às expectativas neodesenvolvimentistas. Ao mesmo tempo, há indícios de que as "campeãs nacionais" acessaram créditos de longo prazo para reduzir custos de capital, ou mesmo para lucrar por meio da manipulação das taxas de juros, em operações de arbitragem (BONOMO et al., 2014).

3 Condenado anteriormente a 23 anos de prisão, Leo Pinheiro deixou a cadeia em setembro de 2019.
} 
se evidenciou nas Jornadas de Junho de 2013, maior ciclo de manifestações de rua da história do país. Movimento multifacetado que gerou interpretações diversas, as jornadas gravitaram em torno a três questões fundamentais: democratização das cidades, políticas públicas universais e uma reação ao cretinismo parlamentar. Embora não se dirigisse especificamente contra o PT, era evidente que a rebelião contestava a modernização conservadora aprofundada pelo partido, e assim, o incluía. No entanto, as jornadas de junho também sinalizaram o fim da paz lulista do ponto de vista das classes dominantes, pois se explicitou que a capacidade petista de mediar as tensões sociais estava comprometida. Para fazer uma figura de imagem: se o PT ganhou seu lugar na política colocando o povo nas ruas nos anos 1980, e chegou a Brasília tirando-o das ruas nos decênios seguintes, em junho de 2013 ficou claro que o partido não tinha mais poder para colocar, nem para tirar o povo das ruas.

A convergência entre junho de 2013, os escândalos de corrupção geridos como espetáculos pela mídia corporativa nos anos seguintes, e a crise econômica que desembocou em recessão a partir de 2015, produziu um deslizamento para a direita da abordagem das classes dominantes, que pode ser sintetizado em duas ideias: a passagem de um 'neoliberalismo inclusivo' para a espoliação social, e da conciliação para a guerra de classes. É esse o pano de fundo dos acontecimentos recentes da política brasileira, entre a deposição de Rousseff em 2016, a prisão de Lula e a eleição de Bolsonaro em 2018.

\section{Bolsonarismo para além de Bolsonaro}

Entretanto, a sequência entre um processo político ilegítimo, senão ilegal, que culminou com a deposição de Rousseff; dos abusos decorrentes da instrumentalização da Lava Jato contra o PT em meio à colusão do judiciário com a mídia, transformando juízes em celebridades e julgamentos em novelas; da prisão de Lula, que inviabilizou sua candidatura em uma eleição onde despontava como favorito; a nomeação do juiz que condenou Lula, Sergio Moro, como ministro da Justiça do governo Bolsonaro; a revelação de evidências inquestionáveis da atuação interessada deste juiz no processo contra Lula; esta sucessão de atropelos teve como resultado um efeito inverso ao declarado, pois, em lugar de promover uma nova ética, terminou instaurando um desrespeito pela legalidade e pelas instituições, da qual se alimenta Bolsonaro (ANDERSON, 2019, p. 129). 
Vista em perspectiva estrutural, esta crise de legitimidade pode ser interpretada como sintoma de um movimento mais amplo, que se evidenciou nas eleições presidenciais de 2018. Neste pleito, a economia não esteve em disputa, pois o vencedor enfrentaria os problemas do neoliberalismo com mais neoliberalismo - seja na versão inclusiva defendida pelo PT, seja na modalidade fundamentalista proposta por Bolsonaro. Por baixo dos personagens, o que a burguesia discute é a cara do arranjo político, jurídico e cultural que substituirá a Nova República, definitivamente condenada. A dispersão de candidatos expressa esta busca por um caminho, que também se observou na eleição vencida por Collor de Mello há trinta anos, quando a Nova República começava. Novamente, a burguesia busca um caminho, mas agora para enterrá-la. Entre estes dois momentos, todos os pleitos foram polarizados por PT e PSDB.

Neste sentido, há um elemento acidental na eleição de Bolsonaro. Posto que os três candidatos que representavam explicitamente o capital não somaram $10 \%$ dos votos ${ }^{4}$, a ordem se perfilou atrás do capitão. Porque o sentido da história, no Brasil como no mundo, é na direção de regimes em que se acentua a colusão entre neoliberalismo e autoritarismo, entre violência econômica e repressão política.

Nesta perspectiva, não há mistério na adesão dos de cima à Bolsonaro. Embora xucro e vulgar, a violência que ele encarna é, em primeiro lugar, uma violência de classe. A lógica dos ricos foi explicada por seu poderoso ministro da economia, Paulo Guedes: "Aí chega um sujeito completamente tosco, bruto e consegue voto como o Lula conseguiu. A elite brasileira, em vez de entender e falar assim, pô, nós temos a oportunidade de mudar a política brasileira para melhor [...] ah, mas ele xinga isso, xinga aquilo... Amansa o cara!". Perguntado se era possível amansar Bolsonaro, Guedes sentenciou: "Acho que sim, já é outro animal" (GASPAR, 2018). Domesticar a fera em prol de seus interesses de classe, é essa a aposta dos de cima.

O drama é a adesão popular. Na ausência do líder carismático, o subproletariado que sustentou o lulismo pendeu para Bolsonaro, exceto no nordeste do país. Todo brasileiro conhece quem já votou em Lula e, agora, elegeu o capitão. Descartando-se a hipótese de que

\footnotetext{
4 Geraldo Alckmin, então governador de São Paulo, candidato pelo PSDB; Henrique Meirelles, que assumiu a ingrata candidatura do partido de Temer; e João Amoedo, representando um novo partido de ricos brasileiros, que adotou esse mesmo nome: Partido Novo.
} 
todos que nele votaram são fascistas ou foram manipulados contra o PT, este deslizamento sugere a incômoda hipótese de que o bolsonarismo é o negativo do lulismo (no sentido fotográfico) e não sua negação.

$\mathrm{Na}$ leitura de André Singer, que pode ser considerada como a mais elegante racionalização do conservadorismo petista no poder, argumenta-se que a maioria do povo brasileiro entende que o Estado deve cumprir um papel social, mas tem aversão a radicalismos, identificados com uma desordem que lhes ameaça. Singer também descreve a autonomização do lulismo em relação ao PT, um fenômeno político que dialoga com o perfil destes eleitores pobres, que antes votavam na direita, mas, com o tempo, aderiram a Lula (SINGER, 2012). Com seu discurso personalista e autoritário, falando em fechar o Congresso para fazer as coisas, Bolsonaro oferece uma versão diferente de liderança, de ordem e do Estado. Como Lula, o ex-capitão se comunica com o povo, ainda que de modo perverso, pois maneja a linguagem da brutalidade, que um povo brutalizado conhece e entende. Mais grave, com seu jeito vulgar, mas franco, o militar vendeu-se como alternativa ao establishment, com o qual o PT é identificado por grande parte da população, principalmente a juventude. Para além dos votos reacionários, que não foram poucos, muitos tiveram um teor de protesto como o voto no PT nas suas origens. Pesquisas constataram que, durante a campanha, eleitores da periferia hesitavam entre o voto em Lula ou em Bolsonaro (PINHEIRO MACHADO; SCALCO, 2018).

Eleito em uma campanha na qual mobilizaram-se valores, Bolsonaro não mostrou um programa. Na realidade, ele ofereceu a moldura deste neoliberalismo autoritário, que é o Estado policial. Mas o seu conteúdo é terceirizado para o grande capital, que encontrou seu fiador no ministro da Economia Paulo Guedes5. Pós-graduado em Chicago, nos anos 1970, colega dos famosos Chicago boys chilenos, Guedes trabalhou neste país na década seguinte, quando a universidade estava sob intervenção militar. Sua visão da economia brasileira é resumida na seguinte passagem: "A 'direita' hegemônica governou por duas décadas, e a 'esquerda' hegemônica por três, ambas com um modelo econômico dirigista, desastroso para o desenvolvimento social e político do país" (GUEDES, 2017).

\footnotetext{
${ }^{5}$ A mensagem por trás de seu comportamento aparentemente ingênuo na campanha, quando se recusou a responder questões sobre economia dizendo que seu ministro as endereçaria, era que Bolsonaro não se envolveria na gestão econômica, dando liberdade aos quadros do mercado.
} 
Esta crítica a um 'dirigismo' econômico que teria atravessado a ditadura, tucanos e petistas, revela que a inspiração de Guedes é o Chile de Pinochet. Para além da agenda econômica, é plausível que Bolsonaro tenha se seduzido pelos efeitos sociais deste experimento neoliberal radical. O objetivo político da reorganização total das relações sociais em uma direção mercantil empreendida pela ditadura, foi esvaziar toda possibilidade de organização coletiva, e, em última análise, de resistência. Referência de modernidade na região até outubro passado, o país era internacionalmente percebido como um caso de neoliberalismo que deu certo, justamente por sua estabilidade. A rebelião chilena contra esta sociedade do desamparo, certamente repercutiu em Brasília.

Concretamente, o governo Bolsonaro implementa uma agenda antipopular que compromete a letra e o espírito da Constituição de 1988. É certo que, desde a sua promulgação, a Carta Magna foi remendada com frequência (BERCOVICl; MASSONETO, 2006). Retrospectivamente, é evidente que a noção de direitos sociais referida a um Estado de bem-estar periférico, se afirmou no Brasil em um momento em que o ideal de uma cidadania salarial recuava em ritmo acelerado no mundo ${ }^{6}$. No entanto, a centralidade dos direitos sociais, embora sabotada na prática, tinha sido até então preservada.

Deste ponto de vista, o governo Temer marca uma inflexão, mas os ventos já sopravam nesta direção. Em 2015, Rousseff implementou o programa do candidato que derrotou nas eleições em 2014, levando sua base a acusá-la de "estelionato eleitoral". A presidenta caiu sem luta, negociando e cedendo com aqueles que a derrubavam e, como um de seus últimos gestos, assinou a lei-antiterrorista em um país onde, todos sabem, não há terrorismo. Temer implementou uma reforma trabalhista que abriu caminho para universalizar as terceirizações e o trabalho intermitente, desmontando o alicerce de uma cidadania salarial. Em seguida, congelou por vinte anos os gastos públicos sociais (restritos à correção inflacionária), por meio da emenda constitucional 95 que, por outro lado, não limita o serviço da dívida. Por fim, pretendeu avançar uma reforma da previdência, mas a convergência entre protestos de rua e denúncias de corrupção imobilizaram o governo a partir de meados de 2017.

\footnotetext{
${ }^{6}$ É pertinente recordar que os deputados constituintes do PT não assinaram a nova Carta Magna, porque a consideraram muito aquém das exigências sociais da população brasileira.
} 
Esta agenda impopular, mas consensual entre a burguesia, foi retomada com ímpeto por Bolsonaro. A reforma da previdência foi interpretada pelo capital como um teste para o novo governo, de modo comparável ao que ocorrera com Lula em 2003, quando se reformou a previdência dos servidores públicos 7 . O debate sobre o tema foi conduzido de modo falaz, mas revelador. Para transmitir a ideia de que o sistema previdenciário tinha um rombo prestes a explodir, apresentavam-se as receitas dos contribuintes na ativa, contra as despesas correntes com aposentadorias. Porém, a previdência no Brasil é parte do sistema de seguridade social definido pela Constituição, que prevê um financiamento tripartite (trabalhadores, empregadores e governo) e não é deficitário. Somente em anos recentes apresentou um pequeno déficit, mas porque o estado tem desvinculado receitas do sistema, desviando seus aportes para outros fins.

Uma lógica similar perpassa a reforma administrativa proposta pelo governo, que, entre outros itens, prevê a desvinculação total das receitas federais, desobrigando despesas com saúde, educação, previdência, folha de pagamento e assim por diante. Depois de estabelecer um teto para a despesa social com a emenda constitucional 95 sob Temer, a ideia, agora, é modificar o seu piso. Mais ainda, a intenção é sobrepor aos direitos sociais constitucionais um 'direito ao equilíbrio fiscal'. Segundo o artigo $6^{\circ}$ da Constituição: "São direitos sociais a educação, a saúde, a alimentação, o trabalho, a moradia, o transporte, o lazer, a segurança, a Previdência Social, a proteção à maternidade e à infância, a assistência aos desamparados, na forma desta Constituição". A emenda constitucional proposta por Guedes acrescenta, em um parágrafo único: "Será observado, na promoção dos direitos sociais, o direito ao equilíbrio fiscal intergeracional" (BRASIL, 1988). Em outras palavras, direitos que comprometem as contas públicas não são garantidos, com o argumento de que é necessário preservar os direitos das gerações futuras. Esta emenda compromete, inclusive, decisões judiciais, uma vez que o ganho de causa não implica o cumprimento da demanda, condicionada ao 'equilíbrio fiscal'. A hierarquia entre os direitos do capital e os direitos do cidadão é aberrante, mas transparente.

\footnotetext{
7 No primeiro ano do governo Lula, aprovou-se uma reforma da previdência, emblemática por dois motivos: porque substituiu a lógica da solidariedade geracional (em que os trabalhadores ativos sustentam os aposentados), por um modelo em que cada trabalhador tem uma conta, gerida como um produto financeiro. Mas também porque revelou a capacidade de persuasão do partido no poder, uma vez que a mesma agenda tinha sido brecada no governo anterior pela resistência de centrais sindicais e do próprio PT.
} 
Outra ilustração da incompatibilidade entre o programa do governo e o marco constitucional vigente é a proposta do senador Flávio Bolsonaro de alterar os critérios da 'função social da terra', figura constitucional que fundamentou a luta por reforma agrária desde o fim da ditadura. Atualmente, a função social implica quatro exigências: ser produtiva, utilizar os recursos naturais de maneira adequada, respeitar as relações de trabalho e favorecer o bem estar dos proprietários e colaboradores. A emenda exige o cumprimento de apenas uma dentre as quatro condições para que a terra cumpra uma função social, o que, entre outras consequências, desqualifica o desmatamento ou o trabalho escravo como motivos para desapropriação.

Esta agenda antipopular arquitetada por Guedes, comprometendo os fundamentos da Constituição Cidadã, tem a adesão das classes dominantes. E, no entanto, seu apoio a Bolsonaro não é seguro. O discurso dominante da alta burguesia é que o militar é uma figura 'desagradável', como disse a francesa Marine le Pen, mas que, na economia, está fazendo o que é preciso. À sua maneira, reedita-se a narrativa liberal sobre a ditadura chilena, que afirma, em linhas gerais, que o regime exagerou na repressão, mas acertou na economia.

A convergência entre neoliberalismo e autoritarismo admite diversas roupagens, entre o nacionalismo hindu de Modi, a guerra às drogas de Duterte e o 'America First' de Trump. Pode-se dizer que o ideal da classe dominante brasileira é um bolsonarismo sem Bolsonaro: talvez estejam em busca do seu Macron. O ministro da Justiça Sergio Moro, o governador de São Paulo João Dória, o apresentador de televisão Luciano Huck ${ }^{8}$ estão entre os candidatos. Na ausência de Bolsonaro, os dois últimos compareceram ao Fórum Econômico Mundial em Davos em 2020.

No entanto, Bolsonaro tem ideias próprias, mas, para isso, precisa ter base própria. Porque o outro lado da sua forte presença em redes sociais, decisiva na eleição, é uma frágil organicidade: o presidente tem seguidores antes que militantes. Nas redes sociais, a impossibilidade de sustentar um discurso articulado foi transformada em virtude por seus seguidores. Seu estilo caótico e fragmentado de comunicação, baseado em inversões rápidas, cortes secos e slogans, é talhado para os vídeos curtos da internet, onde ele reina:

\footnotetext{
${ }^{8}$ Guedes estava comprometido com a candidatura de Huck e só aderiu à campanha de Bolsonaro quando o apresentador desistiu de concorrer.
} 
fala no broadcast (a televisão) para o multicast (internet) (LAGO, 2018). Não é casual que, em seu discurso de posse, o presidente agradeceu em primeiro lugar aos internautas.

Para deixar de ser contingente, o principal desafio do presidente é forjar uma base orgânica a partir deste amálgama virtual. Seu plano parece ser uma dinastia (tem três filhos na política), tendo como partido as forças armadas e policiais, e como base orgânica, os neopentecostais. Em cada um de seus dias como presidente, tem agenda com estes setores. Ao mesmo tempo, testa a possibilidade de fazer de seus seguidores, militantes. Seu experimento mais ousado nesta direção foi a convocação de uma manifestação reivindicando o fechamento do Congresso Nacional, que tem sido fonte de atrito não por uma oposição ideológica ou moral, mas no terreno da barganha política. O ato previsto para março de 2020 acabou cancelado em função da pandemia do corona-vírus?

É preciso observar que o apelo popular desta agenda reflete sentimentos contraditórios: como observou Pinheiro Machado, na greve dos caminhoneiros em 2018, muitos manifestantes eram críticos do impeachment de Rousseff e, ao mesmo tempo, favoráveis a fechar o Congresso (PINHEIRO MACHADO, 2019). A hostilidade ao Congresso parte da constatação do caráter pútrido desta instituição e não equivale, necessariamente, a apoiar uma ditadura militar. O paradoxo é que Bolsonaro capta e denuncia, de modo perverso, aspectos repulsivos da institucionalidade burguesa, enquanto a esquerda se coloca na posição de a defender. A polêmica com Emmanuel Macron em torno das queimadas na Amazônia revelou uma dinâmica similar, onde muitos se sentiram desforrados pelo "bom senso" do presidente francês, que nada mais é do que a hipocrisia burguesa, à qual estamos todos acostumados. É preciso entender que Bolsonaro é a cara feia, mas real, da crise da sociabilidade burguesa, que é também a crise da sua hipocrisia. É a cara da política em um mundo em que as mediações entre cultura e barbárie se borram. Bolsonaro não é o contrário desta cultura (o contrário de Macron), mas o seu produto, superficialmente rebelde. (FELDMANN; SANTOS, 2019). Confrontado com Bolsonaro, o progressismo arrisca a se tornar conservador, quando não restauracionista.

\footnotetext{
$9 \mathrm{O}$ ato previsto para 15/3/2020 terminou cancelado em função do coronavírus, mas alguns insistiram em manifestar-se e foram cumprimentados pessoalmente pelo presidente, contrariando recomendações elementares das autoridades sanitárias do país e do mundo. Por sua vez, esta imprudência alimentou um panelaço contra o presidente três dias depois, quando a maior parte dos brasileiros estavam confinados em suas casas. É um primeiro sintoma de que o militar pode vir a ser contestado também pelos de baixo.
} 


\section{Esquerda contra a barbárie?}

Este é o dilema da esquerda brasileira: se centrará forças em defender a constituição (burguesa), as instituições (conservadoras), a democracia (liberal), o parlamento (cretinizado); ou se radicalizará a crítica, ampliando o horizonte de reflexão e de ação. O ponto de partida para o segundo caminho é enfocar a política como um amplo terreno de disputa social, que tem nas eleições apenas uma expressão, embora importante.

Encarada deste ponto de vista, a vitória de Bolsonaro foi um revés importante, mas está longe de ser conclusivo. Conforme já observamos, a visão de mundo de muitos brasileiros é contraditória, como a própria realidade em que vivem - por exemplo, conhecem uma polícia que bate, mas que também pode defendê-lo; ou uma uberização que lhes suga, mas sem patrão: "todo trabalhador precarizado carrega a indignação de viver numa sociedade desigual e a manifesta de formas contraditórias" (PINHEIRO MACHADO, 2019). Estas contradições podem ser mobilizadas por um projeto autoritário, mas também carregam potência de mudança.

Neste sentido, Bolsonaro ganhou uma eleição, mas não necessariamente os corações e as mentes dos que nele votaram. O problema maior é a bolsonarização da sociedade, que está em curso há muito tempo. Isso porque a dinâmica da reprodução social neoliberal se converteu, mundialmente, em uma máquina de moer gente que engendra ódio, medo e violência. Visto deste ângulo, a diferença entre as gestões petistas em relação a Bolsonaro é que elas pretenderam moderar o ritmo e a intensidade desta engrenagem, enquanto o militar, pretende acelerá-la. Os primeiros se empenharam em gerir a crise, enquanto o último, governa por meio dela.

O cerne do problema é que, a despeito de eventuais boas intenções dos governantes progressistas (digamos, do PT), a contenção deste movimento dessocializante não impede a sua aceleração. Dito de outra forma, a administração do desmonte da cidadania salarial na atualidade, implica práticas que aceleram a dinâmica social disruptiva.

Examinemos a questão concretamente. Lula enviou o general Augusto Heleno para comandar a missão de paz da ONU no Haiti. Esta participação foi concebida nos marcos da ideia de fazer do Brasil um global player. No entanto, o general e sua tropa voltaram pensando em outra direção: como evitar que o Brasil se torne um Haiti. Não é segredo que os militares 
brasileiros enxergaram na ilha uma oportunidade de treino e experimentação. De volta para casa, muitos se convenceram de que o exército deveria se engajar em missões similares às da ONU, mas no plano doméstico. Por outro lado, cresce a demanda de missões de 'Garantia da Lei e da Ordem' por políticos desejosos de mostrar uma mão dura em todo o país ${ }^{10}$, o que, por sua vez, fortalece o poder de barganha dos militares (HARIG, 2018). Barrado como vice de Bolsonaro por seu partido, Heleno se serve deste repertório para comandar o Gabinete de Segurança da Presidência da República, órgão diretamente vinculado à presidência e responsável pelos serviços de inteligência. Outro veterano do Haiti, o general Fernando Azevedo e Silva, assumiu o ministério da Defesa, uma pasta criada em 1999 com a intenção de reforçar o controle civil sobre as Forças Armadas, e que, até Temer, nunca tinha sido ocupada por um militar. Em 2013, Azevedo e Silva tinha sido nomeado por Dilma para comandar a Autoridade Pública Olímpica.

Entre a ambição global player e as olimpíadas no Rio de Janeiro, os nexos entre o devaneio de um Brasil potência e a gestão armada da vida social vão além da valorização civil dos militares. Seu pano de fundo é a diluição das fronteiras entre a militarização da vida e a assistência social, que se misturaram como areia e cimento nos anos petistas, na tentativa de manter em pé uma sociedade que desmorona.

Segundo a penetrante análise de Paulo Arantes, os militares brasileiros operam em um mundo onde a guerra se torna um 'trabalho social armado', em que não se trata de vencer batalhas, mas de pacificar populações (BACEVICH, 2010). Neste quadro, intervenções militares no Haiti, como no Rio de Janeiro, ganham a roupagem de um trabalho social, cujo sucesso depende da percepção dos moradores em relação à legitimidade do Estado, de onde emana a assistência, mas também a punição. O outro lado destas "operações de contrainsurgência repaginadas como política pública de pacificação" é a conversão dos direitos humanos em técnicas de governo e, em última análise, em políticas públicas também (ARANTES, 2014, p. 368).

\footnotetext{
${ }^{10}$ Realizadas exclusivamente por ordem da Presidência da República, as missões de Garantia da Lei e da Ordem são previstas constitucionalmente em casos de grave perturbação da ordem, em que há o esgotamento das forças tradicionais de segurança pública. Então, é facultado provisoriamente aos militares atuar com poder de polícia. Na prática, seu uso se trivializou (Copa do Mundo, visita do Papa, greves policiais nos Estados) e se estendeu no tempo, problematizando seu caráter provisório.
} 
Assim, a governabilidade afiançada pela polícia e o exército no Rio de Janeiro, laboratório da militarização da vida nos anos petistas, tem como braço complementar uma geração de militantes treinados durante décadas na discussão, formulação e implementação de políticas públicas, atuando como representantes do Estado, do partido, de ONGs ou da comunidade. Neste processo formativo, que acompanhou a sedimentação de um "modo petista de governar" após a ditadura, uma cidadania insurgente em potencial foi modelada segundo os requisitos de uma cidadania regulada. Modalidades de participação, balizadas pela institucionalidade estatal, esvaziaram o viés popular e classista do ativismo social: a participação popular se transmutou em participação cidadã, configurando um conjunto de técnicas que desmobilizam, mobilizando. Neste quadro, dizer que nos anos petistas, os brasileiros nunca foram tão participativos (71 conselhos e 74 conferências só no período Iulista), significa reconhecer que nunca foram tão governados. (ARANTES, 2014, p. 431).

Ao mesmo tempo, a engrenagem da "pacificação contrainsurgente" visa transformar os moradores (a 'comunidade') em empreendedores, forjando no processo um "simulacro de uma sociedade civil ativa e propositiva", ambição compartilhada por Estado, Empresas, Terceiro Setor e comunidades. Segundo Arantes, este processo de autoempresariamento sem fim produz uma falsa mercadoria, que atende por diversos nomes: "cidadania, inclusão, participação etc.". A novidade é que, agora, quem segura aberta a porta de entrada para esse "mercado da cidadania", é a polícia (ARANTES, 2014, p. 374).

Em resumo, coerção e serviço social se deram as mãos no Brasil petista para produzir não a paz, mas uma pacificação, que projeta a lógica do mal menor para a favela: em um mundo de expectativas decrescentes, trata-se de convencer a população de que os benefícios de se submeter à autoridade estatal superam os custos, ou seja, que a pressão policial é preferivel à opressão do tráfico, ou aquela mais organizada, das milícias. Em todo caso, o que se evidencia é que a inclusividade petista nunca foi o contrário do punitivismo bolsonarista, mas o pressupôs, o complementou e o reforçou.

A contradição desta lógica, em que a tentativa de conter o movimento dessocializante não impede a sua aceleração, pois implica fortalecer justamente o que se pretende conter, pode ser constatada em múltiplos planos. Ilustrações epidérmicas incluem: o ex-presidente mundial do Bank Boston, Henrique Meirelles, que renunciou como deputado tucano em 2003 para comandar o Banco Central por oito anos sob Lula e que, depois, foi ministro da economia sob Temer; a tentativa do governo Lula de fazer ligação direta com o "baixo clero" no 
Congresso que desatou o escândalo do 'mensalão' em 2005, respondido com mais espaço para o PMDB no governo, levando o partido a indicar o futuro golpista Michel Temer por duas vezes como vice-presidente na chapa de Rousseff; o apoio de lideranças neopentecostais às administrações petistas, que resultou em recuos na agenda comportamental e na nomeação de ministros evangélicos como Marcelo Crivella, que, em 2016, derrotou no Rio de Janeiro um dos únicos candidatos da esquerda a chegar no segundo turno nas eleições para prefeito; as construtoras, que não hesitaram em mandar para a cadeia, em delações reais ou imaginárias, aqueles que lhes abriram caminho para ganhar dinheiro como nunca; isso para não falar nos jovens que encararam o precariado como fase transitória de uma ascensão social que passava pelo crédito e a universidade privada mas que, uma vez atingidos pela crise e o desemprego, transformaram a esperança em ódio; ou de movimentos sociais neutralizados por políticas visando neutralizar sua combatividade em lugar de implementar suas bandeiras (como a reforma agrária e urbana), resultando, treze anos depois, em um campo popular dividido, debilitado e desprestigiado.

Em resumo, os militares, os bancos, o PMDB, o vice-presidente Michel Temer, o neopentecostalismo, as empreiteiras, o empreendedorismo, a passividade, foram todos alimentados e cultivados, em seu momento, pelos governos petistas. Neste quadro, a figura de imagem mais adequada da relação entre a defenestração do PT e a ascensão de Bolsonaro não é uma guinada de 180 graus, mas uma metástase, na medida em que forças e interesses corrosivos, cujo poder nunca foi desafiado e que pareciam controladas sob o petismo, agora se espalham inconteste pelo tecido nacional. Em síntese, podemos aventar um processo de 'contenção aceleracionista' em que o pretendido progressismo petista, a despeito das intenções, transformou-se no seu oposto (FELDMANN; SANTOS, 2020).

É sob esta perspectiva que se deve enquadrar a discussão da esquerda brasileira. $O$ diagnóstico acima coloca em xeque o chamado projeto 'democrático-popular', em torno do qual gerações militantes se aglutinaram após a ditadura, convergindo no $\mathrm{PT}^{11}$. Diante da contra-revolução permanente que se impôs como projeto burguês desde o golpe de 1964 (FERNANDES, 1975), em uma quadra histórica de crise permanente do capital (MESZAROS,

\footnotetext{
${ }^{11} \mathrm{Em}$ linhas gerais, previa-se a convergência de duas pinças: a ocupação de cargos eletivos pelo partido, acompanhada da pressão popular nas ruas, provocaria uma situação em que reformas dentro da ordem desembocariam em reformas contra a ordem.
} 
1999), a única reforma possível é uma gestão da crise (um 'modo petista de governar') que, no entanto, a agrava. Não se trata de uma escolha racional de agentes históricos (uma 'traição'), mas da imposição irracional, cega e impessoal da lógica da produção do valor ao governo das pessoas, em uma época de crise do valor (KURZ, 1993; MENEGAT, 2019) ${ }^{12}$. Por outro lado, o fim da Nova República significa que esta política de pretensão reformista não tem mais chão histórico em que se apoiar, em um mundo onde neoliberalismo e autoritarismo convergem.

Embora esta leitura indique que o PT se tornou anacrônico, paradoxalmente, a eleição de Bolsonaro deu um sopro de vida ao partido, interpretado por muitos como a única tábua de salvação possível diante do tsunami. Sem diminuir a gravidade do momento, é preciso observar que esta retórica do pânico é funcional ao lulismo, pois visa blindar o debate e a emergência de alternativas pela esquerda, taxadas como inoportunas em um momento de necessária unidade. O antídoto ao pânico não é a aliança, mas a crítica (OLIVEIRA; PERRUSO; SANTOS, 2020).

Do ponto de vista da esquerda, uma hipotética frente ampla exige clareza sobre a natureza dos aliados, sobretudo do lulismo. O PT é um partido da ordem e, como tal, sua preocupação central é a sorte do partido e, somente de modo acessório, o destino do país. É claro que, na ideologia de seus quadros mais fiéis, a salvação do país se identifica com a ressureição do partido. Mas, do ponto de vista da esquerda, a política do partido e a das ruas frequentemente diverge: o 'fora Temer' foi brecado diante da certeza da vitória de Lula, e quando Bolsonaro se elegeu alguns petistas comemoravam, em meio ao luto geral, o crescimento da bancada do partido. Este descolamento atingiu o paroxismo quando o partido decidiu não aderir ao 'fora Bolsonaro', apesar da conduta genocida do presidente no contexto da pandemia do coronavírus (LINHARES, 2020). Como um peixe de Brasília, o PT pode até se fortalecer em meio a tsunamis, enquanto o povo se afoga.

Essa constatação não impede que a esquerda forme uma frente tática com o PT, mas torna duvidoso que o PT queira formar uma frente de esquerda, o que é diferente de uma

\footnotetext{
${ }^{12}$ A ideia fundamental é que inovações produtivas nos decênios recentes levaram ao paroxismo a contradição do capital de exigir trabalho (para produzir valor) e expulsá-lo (inovação tecnológica), resultando em crise estrutural que se expressa na valorização do valor mas também gera uma massa de gente sem trabalho, descartável segundo a racionalidade do sistema, mas que precisa ser gerida.
} 
frente com a esquerda. Ao partido, só interessam alianças que o cacifem como alternativa da ordem e, para este objetivo, buscou e buscará uma frente com o capital. O sonho do partido é que Bolsonaro se dissipe como um pesadelo, a normalidade burguesa seja reestabelecida e, com ela, eleições limpas, nas quais o partido tem um cavalo sempre no páreo. O partido sonha com a Argentina, onde o kirchnerismo perdeu uma eleição, esperou quatro anos e voltou à Casa Rosada, ainda que na vice-presidência. Seu pesadelo, é o Chile. A diferença entre Argentina e Brasil, em relação ao Chile, é que este último não tem um messias para se ajoelhar, só um futuro ${ }^{13}$. Enquanto corações e mentes daqueles que anseiam por mudança estiverem com Lula, no Brasil não haverá Chile.

Quem já entendeu que não haverá salvação por meio de eleições, deve olhar a política além de Brasília. Em meio a sentimentos e experiências de vida contraditórias, disputas acontecem na sociedade. Um exemplo pertinente é a luta feminista. Duas semanas antes da eleição presidencial em 2018, as ruas de muitas cidades brasileiras foram tomadas por uma massiva manifestação liderada por mulheres, sob a consigna 'Ele não'. Quem participou deste momento comovente, teve certeza de que 'ele' não passaria.

No entanto, duas semanas depois, Bolsonaro venceu as eleições e, evidentemente, teve o voto de muitas mulheres. É certo que uma máquina de fake news deturpou os fatos, circulando fotos de mulheres com seios de fora ou se beijando, para retratar a manifestação como uma ameaça aos valores da família cristã, o que tem apelo junto a setores conservadores evangélicos como católicos. O ponto é que, na sociedade brasileira atual, as duas forças coexistem: o conservadorismo moral, mas também um avanço das lutas feministas, que parece irresistível. Uma manifestação semelhante parecia inconcebível vinte ou dez anos atrás.

Visto sob este prisma, o voto em Bolsonaro também pode ser lido como uma reação violenta e desesperada, principalmente de homens, mas também de mulheres, que sentem seu lugar social ameaçado, mesmo que seja um lugar subalterno. A derrota eleitoral não diminui o feito das mulheres e, ao contrário, nos recorda que a disputa mais importante não

\footnotetext{
13 Nas palavras do líder do MST, João Pedro Stédile: "Lula tem de ser nosso Moisés, convencer o povo a atravessar o Mar Vermelho. Não há outro personagem que possa cumprir esse papel" (STÉDILE, 2019).
} 
acontece em Brasília, mas na sociedade: afinal, o fascismo mobiliza subjetividades, mas não as produz.

A favor da bolsonarização do mundo está o neoliberalismo, que faz da reprodução social uma engrenagem que massifica o ódio, o medo e a indiferença (FELDMANN, 2018). No sentido contrário estão as reservas de coragem, sabedoria e solidariedade dos brasileiros, que exigem formas radicais e criativas de organização. Diante da gravidade dos dilemas atuais, em que a disjuntiva 'socialismo ou barbárie' se reescreve como 'bolsonarismo ou humanidade' em diversas gramáticas nacionais, a subjetividade daqueles que simplesmente defendem a vida os empurra a militarem por outra forma de organização social.

No Brasil e no mundo, a radicalidade emerge como uma exigência histórica. A direita já entendeu isso e está se repaginando. O movimento da história esvazia o capitalismo de sua casca liberal e coloca, em seu lugar, modalidades ultraviolentas de colusão entre neoliberalismo e autoritarismo. Este não é o mundo do Estado de Bem-Estar, dos direitos sociais, da cidadania salarial e do desenvolvimento sustentável, mas do Estado policial, da tirania fiscal, do empreendedorismo e das catástrofes ambientais. A esquerda precisa se reinventar com uma radicalidade à altura da situação, mirando o futuro e não o passado, se quiser voltar a ter relevância histórica. E, quem sabe, salvar o mundo.

\section{REFERÊNCIAS}

ANDERSON, Perry. Brazil Apart (1964-2019). London: Verso, 2019.

BACEVICH, Andrew. Washington rules. New York: Metropolitan books, 2010.

BATISTA JUNIOR, Paulo Nogueira. [Palestra de encerramento no curso de verão sobre países BRICS]. Campinas: Unicamp, 2019.

BERCOVICI, G.; MASSONETTO, L. F. A constituição dirigente invertida: a blindagem da constituição financeira e a agonia da constituição econômica. Revista de Ciências Econômicas, Lisboa, n. xlix, 2006.

BOITO JR., A.; BERRINGER, T. Brasil: classes sociais, neodesenvolvimentismo e política externa nos governos Lula e Dilma. Revista Sociologia Politíca, Curitiba, v. 21, n. 47, p. 3138, set. 2013. Disponível em: http://www.scielo.br/ scielo.php?script=sci_arttext\&pid=S0104 44782013000300004\&lng=en\&nrm=iso. Acesso em: 23 mar. 2020. 
BONOMO, M.; BRITO, R.; MARTINS, B. Macroeconomic and financial consequences of the after crisis government-driven credit expansion in Brazil. Working paper 378, Rio de Janeiro, 2014.

BRAGA, R. As Jornadas de Junho no Brasil. In: Plinio de Arruda Sampaio Jr.. (Org.). Jornadas de Junho: a revolta popular em debate. São Paulo: Instituto Caio Prado Jr., 2014, p. $67-84$.

BRAGA, Ruy; SANTOS, Fábio Luis B. dos. The Political Economy of Lulism and Its Aftermath. Latin American Perspectives, v. 46, p. 169-186, dez. 2019. DOI: https://doi.org/10.1177/0094582X19887806

BRASIL. [Constituição (1988)]. Constituição da República Federativa do Brasil de 1988. Brasília, DF: Presidência da República, 1988. Disponível em: http://www.planalto.gov. br/ccivil_03/constituicao/constituicao.htm. Acesso em: 30 nov. 2020.

DARDOT, Pierre; LAVAL, Christophe. La nouvelle raison du monde: essai sur la societé neoliberal. Paris: La Découverte, 2010.

ESPOSITO, Maurício. Desindustrialização do Brasil: uma análise a partir da perspectiva da formação nacional. Revista da Sociedade Brasileira de Economia Política, Niterói, n. 46, 2017.

FELDMANN, Daniel. A crise permanente do capital e os sentidos do novo nacionalismo autoritário no século XXI. [S.l., 2020]. Trabalho inédito não publicado.

FELDMANN, D.; SANTOS, F. L. B. dos. O escracho de Bolsonaro e o bom-senso de Macron. Le monde diplomatique, São Paulo, 05 set. 2019. Disponível em:

https://diplomatique.org.br/o-escracho-de-bolsonaro-e-o-bom-senso-de-macron/. Acesso em: 30 nov. 2020.

FELDMANN, D.; SANTOS, F. L. B. dos. Progressismo e crise estrutural do capital. [S.l., 2020]. Trabalho inédito não publicado.

FERNANDES, Florestan. A revolução burguesa no Brasil. Rio de Janeiro: Zahar, 1975.

GASPAR, Malu. O fiador, Piauí, São Paulo, n. 144, set. 2018. Disponível em: https://piaui.folha.uol.com.br/materia/o-fiador/. Acesso em: 30 nov. 2020.

GUEDES, Paulo. Atolados no pântano. O Globo, Rio de Janeiro, 01 maio 2017. Disponível em: https://oglobo.globo.com/opiniao/atolados-no-pantano-21279887. Acesso em: 30 nov. 2020.

HARIG, Christopher. Re-importing the 'robust turn' in UN peacekeeping: internal public security missions of Brazil's military international peacekeeping. International

Peacekeeping, [S. l.], v. 26, n. 2, p. 137-64, 03 dez. 2018. 
LINHARES, C. PT decide não aderir ao 'fora Bolsonaro' em meio à pandemia do coronavírus. Folha de São Paulo, São Paulo, og abr. 2020. Disponível em: https://www1.

folha.uol.com.br/poder/2020/04/pt-decide-nao-aderir-ao-fora-bolsonaro-em-meio-apandemia-do-coronavirus.shtml. Acesso em: 20 abril 2020.

LAGO, Miguel. Bolsonaro fala outra língua. Piauí, São Paulo, 13 ago. 2018. Disponível em: https://piaui.folha.uol.com.br/bolsonaro-fala-outra-lingua/. Acesso em: 30 nov. 2020.

OLIVEIRA, F. de. Crítica à razão dualista: o ornitorrinco. São Paulo: Boitempo, 2003.

OLIVEIRA, M.; PERRUSO, M. A.; SANTOS, F. L. B. dos. O pânico como política: o Brasil no imaginário do lulismo. [S.l.], 2020. Trabalho inédito não publicado.

KURZ, Robert. O colapso da modernização. Rio de Janeiro: Paz e Terra, 1993.

LEOPOLDO, R. BNDES empresta $391 \%$ mais em 5 anos e supera em três vezes o Banco Mundial. Estado de São Paulo, São Paulo, 10 de mar. 2011.

MENEGAT, M. A crítica do capitalismo em tempos de catástrofe. Rio de Janeiro: Consequência, 2019.

MESZAROS, I. Beyond Capital. New York: Monthly Review Press, 1999.

BRAZIL'S Lula: the most popular politician on Earth. Newsweek, New York, 21 sept. 2009. Disponível em: http://www.newsweek.com/brazils-lula-most-popular-politician-earth79355. Acesso em: 01 dez. 2020.

PINHEIRO MACHADO, R. Amanhã vai ser maior. São Paulo: Planeta, 2019.

PINHEIRO MACHADO, R.; SCALCO, L. M. Da esperança ao ódio: juventude, política e pobreza, do lulismo ao bolsonarismo no Brasil. IHU Unisinos, São Leopoldo, 04 out. 2018. Disponível em: http://www.ihu.unisinos.br/78-noticias/583354-da-esperanca-ao-odiojuventude-politica-e pobreza-do-lulismo-ao-bolsonarismo. Acesso em: 01 dez. 2020.

SAAD FILHO, A.; MORAIS, L. Brasil: neoliberalismo versus democracia. São Paulo: Boitempo, 2018.

SAMPAIO JR., P. de A. Jornadas de junho: a revolta popular em debate. São Paulo: ICP, 2014 .

SAMPAIO JR., P. de A.; SANTOS, F. L. B. dos. The political economy of lulism and its aftermath. Latin American Perspectives, [S. l.], v. 47, n. 1, p. 169-186, 2020.

SANTOS, F. L. B. dos. Neo-development of underdevelopment: Brazil and the political economy of South American integration under PT. Globalizations, [S. l.], v. 16, n. 2, p. 216231, 2018. 
SINGER, A. Os sentidos do lulismo. São Paulo: Companhia das Letras, 2012.

TAUTZ, C.; SISTON, F.; PINTO, J. R. L.; BADIN, L. O BNDES e a reorganização do capitalismo brasileiro: um debate necessário. In: OS ANOS Lula: contribuições para um balanço crítico, 2003-2010. Rio de Janeiro: Garamond, 2010.

\section{UNITED NATIONS INDUSTRIAL DEVENLOPMENT ORGANIZATION. Industrial and Development Report. Viena: UNIDO, 2011.}

\section{Detalhes do autor}

\section{Fábio Luis Barbosa dos Santos}

Doutor em História Econômica pela Universidade de São Paulo. Pós-Doutorado no centro Genre, Travail, Mobilités, Centre de Recherches Sociologiques et Politiques de Paris (GTM-CRESPPA). Professor da Universidade Federal de São Paulo, atuando no curso de Relações Internacionais no campus Osasco. Professor do Programa de Pós Graduação Integração da América Latina (Prolam-USP). Research Associate, Society Work and Politics Institute (SWOP), University of the Witwatersrand, África do Sul. Research Associate, Centre for Canadian, US \& Latin American Studies, School of International Studies, Jawaharlal Nehru University, Índia. Tem experiência na área de História e Relações Internacionais com ênfase em História da América Latina e História do mundo não-europeu, atuando principalmente nos seguintes temas: História Contemporânea; História da América Latina; História do mundo não europeu; Relações Internacionais na América Latina e no Sul Global; Pensamento Brasileiro e Latino-Americano. E-mail: faboroso@gmail.com ORCID: https://orcid.org/0000-0002-5493-9633 